\title{
Oseltamivir for influenza in adults and children: systematic review of clinical study reports and summary of regulatory comments
}

\author{
Tom Jefferson reviewer ${ }^{1}$, Mark Jones senior research fellow (biostatistics) ${ }^{2}$, Peter Doshi assistant \\ professor $^{3}$, Elizabeth A Spencer nutritional epidemiologist ${ }^{4}$, Igho Onakpoya research fellow in \\ evidence-based practice and pharmacovigilance ${ }^{4}$, Carl $\mathrm{J}$ Heneghan professor ${ }^{4}$
}

${ }^{1}$ Cochrane Acute Respiratory Infections Group, Via Puglie 23, 00187 Rome, Italy; ${ }^{2}$ School of Population Health, University of Queensland, Brisbane, Australia; ${ }^{3}$ Department of Pharmaceutical Health Services Research, University of Maryland School of Pharmacy, Baltimore, MD 21201, USA; ${ }^{4}$ Nuffield Department of Primary Care Health Sciences, University of Oxford, Oxford, UK

\begin{abstract}
Objective To describe the potential benefits and harms of oseltamivir by reviewing all clinical study reports (or similar document when no clinical study report exists) of randomised placebo controlled trials and regulatory comments ("regulatory information").

Design Systematic review of regulatory information.

Data sources Clinical study reports, trial registries, electronic databases, regulatory archives, and correspondence with manufacturers.

Eligibility criteria for selecting studies Randomised placebo controlled trials on adults and children who had confirmed or suspected exposure to natural influenza.

Main outcome measures Time to first alleviation of symptoms, influenza outcomes, complications, admissions to hospital, and adverse events in the intention to treat population.

Results From the European Medicines Agency and Roche, we obtained clinical study reports for 83 trials. We included 23 trials in stage 1 (reliability and completeness screen) and 20 in stage 2 (formal analysis). In treatment trials on adults, oseltamivir reduced the time to first alleviation of symptoms by 16.8 hours ( $95 \%$ confidence interval 8.4 to 25.1 hours, $\mathrm{P}<0.001)$. There was no effect in children with asthma, but there was an effect in otherwise healthy children (mean difference 29
\end{abstract}

hours, $95 \%$ confidence interval 12 to 47 hours, $P=0.001$ ). In treatment trials there was no difference in admissions to hospital in adults (risk difference $0.15 \%, 95 \%$ confidence interval $-0.91 \%$ to $0.78 \%, P=0.84$ ) and sparse data in children and for prophylaxis. In adult treatment trials, oseltamivir reduced investigator mediated unverified pneumonia (risk difference $1.00 \%, 0.22 \%$ to $1.49 \%$; number needed to treat to benefit (NNTB) 100, 95\% confidence interval 67 to 451). The effect was not statistically significant in the five trials that used a more detailed diagnostic form for "pneumonia," and no clinical study reports reported laboratory or diagnostic confirmation of "pneumonia." The effect on unverified pneumonia in children and for prophylaxis was not significant. There was no significant reduction in risk of unverified bronchitis, otitis media, sinusitis, or any complication classified as serious or that led to study withdrawal. 14 of 20 trials prompted participants to self report all secondary illnesses to an investigator. Oseltamivir in the treatment of adults increased the risk of nausea (risk difference $3.66 \%, 0.90 \%$ to $7.39 \%$; number needed to treat to harm (NNTH) $28,95 \%$ confidence interval 14 to 112 ) and vomiting (4.56\%, 2.39\% to $7.58 \% ; 22,14$ to 42 ). In treatment of children, oseltamivir induced vomiting $(5.34 \%, 1.75 \%$ to $10.29 \% ; 19,10$ to 57 ). In prophylaxis trials, oseltamivir reduced symptomatic influenza in participants by $55 \%(3.05 \%, 1.83 \%$ to $3.88 \%$; NNTB 33, 26 to 55) and households (13.6\%, 9.52\% to $15.47 \%$; NNTB 7,6 to 11) based on one study, but there was no significant effect on

\footnotetext{
Correspondence to: T Jefferson jefferson.tom@gmail.com

Extra material supplied by the author (see http://www.bmj.com/content/348/bmj.g2545?tab=related\#webextra)

Appendices 1 and 2

CONSORT statement checklist

Index and expected content of a Roche clinical study report

List of excluded studies, with reasons

Statements from Roche

List of included studies

Definitions of influenza

Peer review history of reviews on neuraminidase inhibitors relevant to Cochrane A159

Forest plots: figures 3-30

Data capture for secondary illnesses in oseltamivir trials
} 
asymptomatic influenza and no evidence of a reduction in transmission. In prophylaxis studies, oseltamivir increased the risk of psychiatric adverse events during the combined "on-treatment" and "off-treatment" periods (risk difference $1.06 \%, 0.07 \%$ to $2.76 \%$; NNTH 94, 36 to 1538) and there was a dose-response effect on psychiatric events in two "pivotal" treatment trials of oseltamivir, at $75 \mathrm{mg}$ (standard dose) and $150 \mathrm{mg}$ (high dose) twice daily $(\mathrm{P}=0.038)$. In prophylaxis studies, oseltamivir increased the risk of headaches on-treatment (risk difference $3.15 \%, 0.88 \%$ to $5.78 \%$; NNTH 32,18 to 115$)$, renal events with treatment $(0.67 \%,-0.01 \%$ to $2.93 \%)$, and nausea while receiving treatment $(4.15 \%, 0.86 \%$ to $9.51 \%$; NNTH 25,11 to 116$)$.

Conclusions In prophylactic studies oseltamivir reduces the proportion of symptomatic influenza. In treatment studies it also modestly reduces the time to first alleviation of symptoms, but it causes nausea and vomiting and increases the risk of headaches and renal and psychiatric syndromes. The evidence of clinically significant effects on complications and viral transmission is limited because of rarity of such events and problems with study design. The trade-off between benefits and harms should be borne in mind when making decisions to use oseltamivir for treatment, prophylaxis, or stockpiling.

\section{Introduction}

Influenza antivirals (oseltamivir and zanamivir of the neuraminidase inhibitor class) are commonly used and stockpiled drugs employed against seasonal and pandemic influenza on the basis of international and national recommendations; these recommendations partly justified by the claimed and assumed ability of oseltamivir to reduce complications and transmission of influenza..$^{1-3}$ In theory, containing the spread of influenza allows time for an organised response with longer term interventions (such as vaccines), which take time to produce. ${ }^{3}$ Oseltamivir is now on the list of World Health Organization essential drugs, ${ }^{45}$ but we could not clarify on what basis WHO or the Centers for Disease Control and Prevention recommend its use (www.bmj.com/tamiflu/who, http://www.bmj.com/tamiflu/cdc).

We know that the European CDC relied on a summary of benefits and harms carried out by the European Medicines Agency (EMA), although we have documented that EMA carried out the assessment on (at the most) 15 incomplete reports of oseltamivir trials (www.bmj.com/tamiflu/ema).

Owing to the risk of reporting bias there are legitimate reasons to doubt the stated benefits of oseltamivir and the results of previous Cochrane reviews of neuraminidase inhibitors in adults and children. ${ }^{67}$ To tackle these problems we have conducted a four year campaign to obtain full clinical study reports of the oseltamivir trial programme. Clinical study reports are considered the most exhaustive summaries of randomised controlled trials of drugs. They are usually composed of a main report of the trial (in Introduction, Methods, Results, and Discussion, or IMRAD, style), with numerous appendices containing important supplementary data needed to understand and interpret the trial (for example, protocol, protocol amendments, statistical analysis plan, blank case report forms, certificates of analysis, randomisation list, and informed consent forms $).{ }^{8}$ In the case of oseltamivir, clinical study reports were of mean length approximately 1300 pages (median around 900 pages). As a result of increasing availability, clinical study reports may in the future be incorporated into systematic reviews and other forms of evidence synthesis. ${ }^{7-11}$

Here we report on the part of our Cochrane review on oseltamivir for influenza in adults and children. We succeeded in accessing the reports (the equivalent of the whole Roche sponsored oseltamivir trial programme) in 2013 (www.bmj. com/tamiflu). We report on the first Cochrane review to be based on all relevant full clinical study reports of a drug, augmented by regulatory comments.

\section{Methods \\ Search strategy}

We used a variety of methods applied to different sources (publications, registries, correspondence with manufacturers, and review of regulatory documents) to identify and retrieve manufacturer funded and non-manufacturer funded clinical trials and their clinical study reports. Web extra appendices 1 and 2 detail the methodology for obtaining relevant clinical study reports. We also updated our searches of the electronic databases of published studies previously carried out for the Cochrane reviews on neuraminidase inhibitors in children ${ }^{12}$ and in healthy adults $^{13}$ and then updated the searches again on 22 July 2013.

Our detailed correspondence with Roche is available online at the BMJ open data campaign (www.bmj.com/tamiflu/roche).

\section{Selection of studies \\ Types of studies}

We included randomised controlled trials testing the effects of oseltamivir for treatment, prophylaxis, and post-exposure prophylaxis of influenza. Treatment was the use of oseltamivir in people showing signs of influenza-like illness that might be caused by influenza A and B viruses. Prophylaxis was the mode of use of oseltamivir when there was expectation of possible exposure to influenza in the near future. Post-exposure prophylaxis was the use of oseltamivir after probable exposure to influenza but before symptoms developed. Studies which were open label, and those not involving naturally occurring influenza were excluded.

Because of discrepancies between published and unpublished reports of the same trials, we decided to include only those trials for which we had unabridged clinical study reports. Two authors (PD and TJ) reapplied inclusion criteria for the full clinical study reports received in 2013 and resolved disagreements through discussion.

\section{Types of participants}

Randomised controlled trials had to be in children and adults who either were healthy before exposure to respiratory agents or had a chronic illness (such as asthma, diabetes, hypertension) but excluding people whose immune system had been affected by diseases such as malignancy or HIV infection. Exposure had to be naturally occurring influenza, with or without symptoms. We analysed the intention to treat and safety populations, as our previous review had discovered compelling evidence that the intention to treat influenza infected subpopulation deemed to be influenza infected was not balanced between treatment groups in the oseltamivir trials. In addition, estimates from the intention to treat population are generalisable to clinical practice where routine testing for influenza is not common in many countries (and even where used, remains of variable accuracy).

\section{Types of interventions}

We included trials of neuraminidase inhibitors administered by any route compared with placebo during the period in which treatment was assumed and during the follow-up ("on-treatment" and "off-treatment") periods. 


\section{Types of outcomes}

We divided the outcomes of clinical interest into primary and secondary by indication:

Primary outcome measures for treatment studies-symptom relief, admission to hospital, complications, and harms.

Secondary outcome measures for treatment studies-symptom relapse after finishing treatment, drug resistance, viral excretion, and mortality.

Primary outcome measures for prophylaxis studies-influenza (symptomatic and asymptomatic, always with laboratory confirmation) and influenza-like illness, admission to hospital, complications, interruption of transmission (in its two components, reduction of viral spread from index cases and prevention of onset of influenza in contacts), and harms.

Secondary outcome measures for prophylaxis studies-drug resistance, viral excretion, and mortality.

\section{Data extraction}

Because of the novelty and size of clinical study reports we subdivided the extraction, appraisal, and analysis of the data into a two stage exercise. We included trials meeting our inclusion criteria (that is, had an appropriate study design) in stage 1 . Trials not meeting our inclusion criteria (for example, open label studies) were not included in stage 1 . In stage 1 we assessed the reliability and completeness of the identified trial data. This allowed us to identify missing important text or data. To aid us in determining completeness of the relevant parts of clinical study reports we constructed an extraction form based on the CONSORT statement checklist (see web extra).

We decided to only include data in stage 2 of the review (full analysis following standard Cochrane methods) if they satisfied the following three criteria.

Completeness-clinical study reports include identifiable CONSORT statement specified methods to enable replication of the study. Identifiable CONSORT statement specified results (primary outcomes, tables, appendices) must be available (see web extra appendix 3 for index and expected content of a Roche clinical study report).

Internal consistency - all parts (for example, denominators) of the same clinical study reports or unpublished reports are consistent.

External consistency-consistency of data as reported in regulatory documents, other versions of the same clinical study reports or unpublished reports, and other references, established by cross checking.

This two stage exercise was particularly important in the previous review update (published in January 2012) ${ }^{6}$ when we had received incomplete clinical study reports and were unsure of the importance of the missing parts. However, once we had received full clinical study reports from Roche in 2013, we included all trials meeting our inclusion criteria in stage 1 and those for which the "full" clinical study report was in fact full in stage 2 .

Three reviewers independently carried out data extraction and quality assessment using our customised CONSORT statement forms while a third reviewer arbitrated. Secondly, the extracted data on quality of the studies was again corroborated by a face to face meeting of all authors. Thirdly, we independently cross checked the data on outcomes for statistical analysis to ensure that numbers presented in the forest plots matched actual data from the clinical study reports. Access to full clinical study reports allowed us to follow consistency across chapters and appendices, creating a need for far more interaction with the text. The parts of a clinical study report we checked for consistency included the core report, the pre-study documents, study methodology, individual subject listings of demographic and efficacy data, and individual listings of safety data, as well as the statistical analysis plan and serious adverse events.

We used the Cochrane risk of bias tool ${ }^{9}$ to appraise clinical study reports and a custom built data extraction form for recording information relevant to this appraisal (for example, dates of participant recruitment and date of trial protocol). To deal with the problem of reporting bias, we accessed data from clinical study reports and regulatory information. Owing to the large volume of material at our disposal, we focused on identifying and analysing important details as well as constructing a coherent appraisal of large and complex trial programmes. Because of unrestricted access to full clinical study reports, we took the view that all information needed to judge risk of bias for each of the six domains of the Cochrane risk of bias should be present. When the information was not available, we judged the corresponding risk of bias element as being "high." A full description of the methods used to quantify biases will be published in another paper.

We used relative risks, absolute risks, number needed to treat to benefit (NNTB), and number needed to treat to harm (NNTH) to estimate treatment effects for binary data, and mean differences for time to first alleviation of symptoms. Because of known reporting bias in the oseltamivir evidence base we developed a comprehensive strategy for dealing with unpublished trials (see web extra appendices 1 and 2) and ignored published trials (which are a concentrated summary of clinical study reports).

\section{Data synthesis}

We used relative risks and risk differences to estimate treatment effects for binary data and mean differences for time to first alleviation of symptoms. To estimate treatment effects we first calculated the risk ratios and used the average (mean) control event rate and the pooled risk ratios reported in the figures to calculate the risk differences. For consistency we adopted this method for both the summary of finding tables and for the risk differences reported in the text. For the analysis we chose to report the risk ratios as they are more consistent across the studies, and we have reported the heterogeneity for the pooled risk ratio.

Although overall symptom reduction is well documented, our interest was particularly focused on complications and adverse events, as this is where evidence is currently scarce or inconclusive. ${ }^{6}{ }^{12}$ Our preliminary examination of clinical study reports identified that some symptoms and sequelae of influenza (such as "pneumonia") had been classified as either a "complication of influenza" or as an "adverse event of the treatment," or both. We called this somewhat confusing classification "compliharms." We decided to deal with compliharms as follows. We identified complications of particular clinical interest as "pneumonia," bronchitis, otitis media, and sinusitis. We tabulated the type of data capture used for each complication ("secondary illness") by study (see web extra table 1). The table included the following variables: definition of what events are termed complications, which part of the clinical study report captured data on complications, who reported and captured the data, which diagnostic method was used, whether there was a diagnostic pathway and where (usually a form), and whether prescription for treatment was captured. We then stratified our analysis by method of diagnosis with 
three possible criteria: laboratory confirmed diagnosis (for example, based on radiologically confirmed or microbiologically confirmed evidence of infection), clinical diagnosis without laboratory confirmation (diagnosed by a doctor or investigator after a clinical examination, and other type of diagnosis, such as self reported by patients. We also conducted analysis of any complication (such as "pneumonia," bronchitis, otitis media, and sinusitis) that was classified as serious or led to study withdrawal.

We tested the effects of oseltamivir in prophylaxis of influenza and influenza-like illness. However, the clinical study reports of prophylaxis trials do not define influenza-like illness but report eight different definitions for influenza with laboratory confirmation (see web extra for definitions of influenza).

This is a complex and confusing set of definitions where, for example, the definition for upper respiratory tract infection with systemic disturbance is the same as one of the definitions for asymptomatic influenza. After discovering the absence of a definition for influenza-like illness and the complex and confusing definitions for laboratory confirmed influenza, we classified influenza-like illness as two or more symptoms from the following: nasal congestion, headache, chills or sweats, sore throat, cough, fatigue, myalgia, and fever. These were the symptoms reported in the efficacy listing of individual patients in module 3 of the clinical study reports for the prophylaxis trials.

For harms we were limited by the frequency of occurrence of the adverse events collected in the trials. Consequently we meta-analysed all serious adverse events, all adverse events leading to study withdrawal, all withdrawals, and all adverse events within a defined body system, as well as a small group of common adverse events as defined in the Food and Drug Administration drug labelling for oseltamivir. There were too few events to meta-analyse deaths, serious adverse events by body system, and any events that had an overall incidence of less than $0.5 \%$. We did not meta-analyse outcomes with fewer than 10 events. Analyses were conducted separately for on-treatment and off-treatment periods. However, in two cases where (on-treatment) treatment effects were borderline statistically significant (prophylaxis with oseltamivir: renal body system on-treatment and psychiatric body system on-treatment), we conducted additional analysis combining on-treatment and off-treatment periods to maximise statistical power. We conducted dose-response harms analysis for two treatment trials (WV15670 and WV15671) combined and two prophylaxis trials (WV15673/WV15697) as these trials investigated the active agent at multiple doses. These studies included standard dose and high dose oseltamivir arms. For these analyses we used logistic regression, adjusting for study effects if appropriate (that is, for the two treatment trials) and testing for trend using a likelihood ratio test. We tested the hypothesis that an increased dose of drug leads to an increased incidence of adverse effects.

Using the random effects model of DerSimonian and Laird and inverse variance weighting, we calculated mean differences in time to first alleviation of symptoms and compared incidences of influenza diagnosis, admissions to hospital, complications, and harms between treatment groups. Random effects meta-analysis is known to be overly conservative with sparse data. Hence where we had sparse data and borderline statistically significant results we planned to conduct sensitivity analysis using Peto's method. Harms data were collected in the trials as adverse events classified using the MedDRA dictionary (www. meddra.org). We used $\mathrm{I}^{2}$ values to assess heterogeneity. High estimates of heterogeneity were investigated where possible using subgroup analysis. To investigate heterogeneity of treatment effects for "pneumonia" across all trials that reported this outcome we used metaregression, using metareg command in Stata/SE version 13 for Windows.

A full description of our methods and all the results are available in the complete review published in the Cochrane database. ${ }^{14}$

\section{Review protocol amendments and changes}

The story of the review is long and complex and our methods often reflected the circumstances at the time. The review protocol was first published in 2011 (Jefferson T, Jones MA, Doshi P, Del Mar CB, Heneghan CJ, Hama R, Thompson MJ. Neuraminidase inhibitors for preventing and treating influenza in healthy adults and children-a review of unpublished data. Cochrane Database of Systematic Reviews 2011;1:CD008965. doi:10.1002/14651858) and subsequent amendments were published in 2012 and in the current review (see Feedback/Review Amendments 16 May 2013 ${ }^{6}{ }^{14}$ ).

We have made several changes to the text of our Cochrane review during the process of turning the protocol into the review. This reflects our evolving understanding of the issues, during the relatively long period when work on the review was underway. We have also rewritten the objective twice, tightening up the text to bring it in line with our initial intentions and clarifying its meaning. The old objectives were "To review clinical study reports (CSRs) identified from published and unpublished randomised controlled trials (RCTs) and relevant regulatory data on effectiveness and harms of NIs

[neuraminidase inhibitors] for influenza in all age groups" and "To review published and unpublished clinical study reports and other relevant regulatory data on effectiveness and harms of NIs for influenza in all age groups (and compare them with our published review)." We changed the emphasis of the objectives on unpublished study reports as we had decided from the start to concentrate on regulatory information. Similarly, comparison of published data with unpublished data is an important and worthwhile effort, but the original objective possibly misled readers as to its importance in our work. We had always conceptualised it as a low priority task that we could carry out only if we had time after our review of unpublished data. We have also avoided using acronyms, which we thought cumbersome and confusing to the reader. Our initial intention was to review clinical study reports and regulatory comments making up what we have subsequently called "regulatory information." The edits do not reflect a change in intent but rather our slowly evolving understanding of the problems we faced and our solutions to tackle these problems. As one of many examples, the transition from a world in which studies were identified by names and years (for example, Nicholson 2000), to one in which the same trial is identified by a series of letters and numbers (for example, WV15670), was not easy. While the review was underway, we identified several unforeseen problems, such as placebo content and the effect of oseltamivir on antibodies. To test the relevant hypotheses we carried out post-protocol analyses, which had not been present in the original protocol but were derived from our protocol stated intention to assess programmes and not single trials. These were: hypothesis 1 , the incidence of certain harms is not associated with placebo content; hypothesis 2, oseltamivir (or zanamivir) does not affect antibody production in treatment trials; hypothesis 3 , oseltamivir does not affect antibody production in post-exposure (or secondary prophylaxis) trials; hypothesis 4 , the number of trial centres and centre withdrawals does not affect the proportion of patients receiving placebo who subsequently had a diagnosis of influenza infection (originally the outcome was effect size); and hypothesis 5, in oseltamivir 
treatment trials there is no association between the order of randomisations and nasopharyngeal swabbing (that is, randomising participants first and then swabbing or swabbing participants first and then randomising) and the proportion of patients receiving placebo subsequently having a diagnosis of influenza infection.

These are now reported in their entirety in the "parent" Cochrane review. ${ }^{14}$ The neuraminidase inhibitor comparator changed in the current review. We dropped the original "no intervention" as we realised that none of the clinical study reports had such a comparator, only placebo. In May 2013, we added amendments to the review for data analyses from oseltamivir trials module 2 s, clinical outcomes, and adverse events. ${ }^{14}$

These protocol amendments were motivated by the piecemeal way in which we obtained data over the past four years. There were two major phases of data receipt in the course of the review since year 2009. In the first phase we did not have the full clinical study reports promised by Roche, but instead had 15 incomplete clinical study reports from EMA. These formed the basis for the review update published in the Cochrane Library January $2012 .{ }^{6}$ In that review we corresponded with the manufacturer for key information that was missing from the incomplete study reports in our possession. For example, at www.bmj.com/tamiflu/roche?page $=3$ see a letter from Professor Chris Del Mar to Dr Donald MacLean (Roche) dated 13 April 2011. Del Mar, on our behalf, asked a series of clarification questions on various aspects of the (then) incomplete clinical study reports, but MacLean refused to answer. In the current update of this review, when full clinical study reports were provided by the manufacturer during 2013, we took the view that all risk of bias items should be dealt with in the full clinical study reports and not require supplemental correspondence with manufacturers.

\section{Results}

We identified 83 eligible trials. Twenty three (9623 participants) were included in stage 1 (tables $1 \Downarrow$ and $2 \Downarrow$ ) and 20 in stage 2: 11 on treatment in adults (M76001, WV15670, WV15671, WV15707, WV15730, WV15812/WV15872, WV15819/WV15876/WV15978, WV16277); four in children (WV15758, NV16871, WV15759/WV15871); five on prophylaxis, of which two were in adults (WV15673/WV15697), two in elderly people (WV15708, WV15825), and one in households (WV15799). Sixty studies were excluded (fig $1 \Downarrow$ and web extra), 40 (67\%) of which were pharmacokinetic and $10(17 \%)$ were unblinded or non-comparative studies, or both. We excluded Japanese trials JV15823 and JV15824 and Chinese trial ML16369 from stage 2 because no complete report was available. The first two were synopsis translations and the third was a 50 page Roche-Shanghai internal report.

\section{Risk of bias}

Approximately 48\% (11/23) of studies adequately reported random sequence generation, and 65\% (15/23) showed adequate allocation concealment (fig $2 \Downarrow$ ). Forty eight per cent showed adequate blinding of participants and staff, and 83\% (19/23) showed adequate blinding of outcome assessors. There was high risk of bias for included outcomes as a result of missing data (symptoms), selective reporting (influenza outcomes), potentially active placebo (harms), lack of outcome definitions (complications of influenza), suboptimal measurement (complications), and incomplete reporting in the clinical study reports.
All but three of the oseltamivir treatment trials were under-recruited. We also noted several other items that were not included in all full clinical study reports: study protocols or their amendments in some cases postdated participant enrolment and some protocols were missing altogether. Certificates of analysis for the intervention and placebo preparations were also missing in some cases. The certificates are vital as they furnish a visual description and content of both active and placebo capsules. In many cases the placebo capsule had a different coloured cap to that of the active capsule but this was not remarked on in the report. Participant enrolment dates were not reported, with only trial inception and cessation dates given. No dates for unblinding of the trial database were reported. Authorship and accountability for the writing of the clinical study reports remains unclear. Some names were redacted, but no one seemed to claim responsibility for assembling and writing the reports Complete statistical analysis plans and randomisation codes were missing in some cases, and no study manual of procedures or minutes of safety data monitoring committee meetings were included in any of the clinical study reports. The placebo capsules in oseltamivir trials contained dehydrocholic acid and dibasic calcium phosphate dihydrate (we classified these as other potential biases). Both can cause gastrointestinal symptoms. Although the substances seemed to be in low doses, no discussion of their potential effects in people with fever (as in the treatment trials) was reported.

\section{Benefits}

In the treatment of adults, oseltamivir reduced the time to first alleviation of symptoms by 16.7 hours ( $95 \%$ confidence interval 8.4 to 25.1 hours, $\mathrm{P}<0.001$, see web extra fig 3 ). This represents a reduction in the time to first alleviation of symptoms from 7 days to 6.3 days in the oseltamivir group compared with the control group. In children there was a treatment effect in favour of oseltamivir for otherwise healthy children (mean difference 29 hours, $95 \%$ confidence interval 12 to 47 hours, $\mathrm{P}=0.001$ ) in one trial but no significant effect for children with asthma $(\mathrm{P}=0.53)$ in three trials, leading to considerable heterogeneity $\left(\mathrm{I}^{2}=75 \%\right.$ ) (see web extra fig 4$)$. Because of the selection bias in treatment trials we did not carry out analyses by influenza infected status.

In the treatment of adults there was no difference in rates of admission to hospital between treatment groups (risk ratio 0.92, $95 \%$ confidence interval 0.57 to $1.50, \mathrm{I}^{2}=0$; risk difference $0.15 \%, 95 \%$ confidence interval $-0.91 \%$ to $0.78 \%$, see web extra fig 5). In children (see web extra fig 6), and in prophylaxis trials (see web extra fig 7) there was no significant effect on admissions to hospital. All oseltamivir studies (except for three) collected data on complications through participant self reporting, mediated by an investigator who filled out a form (see web extra table 1). This type of data capture was only identified by examination of the blank case report forms provided in the clinical study report. In six studies, data on complications were captured on a non-specific form, which was generically allocated for recording either secondary illnesses, intercurrent illnesses, or adverse events. In five other studies there were specific case report forms for diagnosing complications, which contained a space to capture diagnostic tests such as chest radiography, tympanometry, and sinus radiography for all secondary illnesses (see web extra table 1), but there was no reporting of such variables in the clinical study reports. Oseltamivir had no significant treatment effect in adults for sinusitis (see web extra fig 8), bronchitis (see web extra fig 9), and otitis media (see web extra fig 10), or complications classified as serious or that led to study withdrawal (see web 
extra fig 11 for adults and web extra fig 12 for children). We observed similar results in children (data not shown), although the data were fewer, with wide confidence intervals.

In the treatment of adults, oseltamivir reduced investigator mediated unverified pneumonia (risk ratio $0.55,95 \%$ confidence interval 0.33 to $0.90, \mathrm{I}^{2}=0 \%$; risk difference $1.00 \%, 95 \%$ confidence interval $0.22 \%$ to $1.49 \%$; Number needed to treat to benefit (NNTB) 100, 95\% confidence interval 67 to 451 , see web extra fig 13). There was no significant difference for the five trials that recorded "pneumonia" on a more detailed case report form (risk ratio $0.69,0.33$ to $1.44, \mathrm{I}^{2}=0 \%$, see web extra fig 13). There was no significant effect in children (1.06, 0.62 to $1.83, \mathrm{I}^{2}=0 \%$, see web extra fig 14 ). No clinical study report reported laboratory confirmation of diagnosis of "pneumonia" and other secondary illnesses (complications) data, which were presumably captured based on the design of the more detailed blank case report forms.

In metaregression of "pneumonia" based on 32 included studies of neuraminidase inhibitors, results showed treatment effects were not statistically different by age group (adults versus children, $\mathrm{P}=0.22$ ), drug (oseltamivir versus zanamivir, $\mathrm{P}=0.89$ ), or indication (treatment versus prophylaxis, $\mathrm{P}=0.14$ ). However, there was evidence that treatment effects were statistically different by type of case report form (generic versus specific form for "pneumonia" diagnosis, $\mathrm{P}=0.025$ ). In oseltamivir studies the risk ratio (treatment effect) was 0.50 (95\% confidence interval 0.27 to $0.90, \mathrm{I}^{2}=0 \%$ ) in studies using a non-specific form for capture of diagnosis of "pneumonia" (nine studies) and 0.93 (0.59 to $\left.1.47, \mathrm{I}^{2}=0 \%\right)$ in studies using a specific form for capture of diagnosis of "pneumonia" (five studies). Web figure 15 shows a forest plot of this analysis.

In prophylaxis trials, oseltamivir reduced symptomatic influenza in participants by $55 \%$ (risk ratio $0.45,95 \%$ confidence interval 0.30 to $0.67, \mathrm{I}^{2}=0 \%$; risk difference $3.05 \%, 95 \%$ confidence interval $1.83 \%$ to $3.88 \%$; NNTB $33,95 \%$ confidence interval 26 to 55 , see web extra fig 16); as well as households $(0.20$, 0.09 to $0.44 ; 13.6 \%, 9.52 \%$ to $15.47 \%$; NNTB 8,7 to 11 ) based on one study (see web extra fig 17). There was no significant effect on asymptomatic influenza - that is, evidence of infection such as increases in antibody titres in the absence of symptoms (see web extra fig 18). In prophylaxis trials we could not analyse effects on influenza-like illness because of a lack of definition in the clinical study reports. However, using our definition (see methods), oseltamivir did not reduce influenza-like illness in participants (risk ratio $0.95,0.86$ to 1.06 ).

The Roche trial programme assessing the effects of oseltamivir in post-exposure prophylaxis submitted to the FDA on 22 May 2000 consisted of two trials: WV15799 and WV16193. We included only trial WV15799 because WV16193 was not placebo controlled. WV15799 was a double blind, cluster randomised trial in which contact clusters of index cases were randomised to oseltamivir $75 \mathrm{mg}$ a day or placebo for seven days. The manufacturer concluded that the trial proved that oseltamivir could prevent influenza in contacts by interrupting transmission from index cases. Interruption of transmission has two components: reduction of viral spread from index cases (measured by nasal shedding of influenza viruses) and prevention of onset of influenza in contacts, measured with a mixture of symptoms and signs and "laboratory confirmation" (that is, viral culture from the upper airways or at least a fourfold increase in antibody titres measured between baseline and two to three weeks later, or both). The design of trial WV15799 is weak. All index cases were left untreated except for a paracetamol rescue pack, making it impossible to assess the effect of oseltamivir on nasal voidance in index cases. Nasal viral voidance was measured only in symptomatic participants thereby missing out on potential asymptomatic people who were infected.

\section{Harms}

In oseltamivir treatment of adults, the proportion being diagnosed as influenza infected at baseline was lower in the oseltamivir group than control group (risk difference 3.34\%, $0.67 \%$ to $6.0 \%$; NNTH 30,17 to 150 ), and the proportion of patients with fourfold increases in antibody titres was significantly lower in the oseltamivir than control group (risk ratio $0.92,0.86$ to $0.97, \mathrm{I}^{2}=4 \%$; risk difference $4.71 \%, 1.77 \%$ to $8.24 \%$; NNTH 22, 13 to 57 , see web extra fig 19). The baseline differences are identifiable only retrospectively, as influenza diagnosis, partly based on antibody response, is made during a 2-4 week follow-up period. Oseltamivir in the treatment of children reduced the proportion with fourfold increases in antibody titres $\left(0.90,0.80\right.$ to $1.00, \mathrm{I}^{2}=0 \% ; 6.14 \%, 0.0 \%$ to $12.28 \%$; NNTH 15,9 to $>1000$, see web extra fig 20). These outcomes were tested according to post protocol hypothesis 2 .

Oseltamivir in the treatment of adults was associated with an increased risk of nausea $\left(1.57,1.14\right.$ to $2.51, \mathrm{I}^{2}=42 \% ; 3.66 \%$, $0.9 \%$ to $7.39 \%$ ); NNTH 28,14 to 112 , see web extra fig 21 ) and vomiting $\left(2.43,1.75\right.$ to $3.38, \mathrm{I}^{2}=0 \% ; 4.56 \%, 2.39 \%$ to $7.58 \%$; NNTH 22, 14 to 42 , see web extra fig 22). Oseltamivir was also associated with a decreased risk of diarrhoea $(0.67$, 0.46 to $0.98, \mathrm{I}^{2}=44 \% ; 2.33 \%, 0.14 \%$ to $3.81 \%$; NNTB 43,27 to 709 , see web extra fig 23 ) and cardiac body system events $\left(0.49,0.25\right.$ to $0.97, \mathrm{I}^{2}=0 \% ; 0.68 \%, 0.04 \%$ to $1.00 \%$; NNTB 148 , 101 to 2509 , see web extra fig 24) compared with placebo during on-treatment periods.

There was no significant difference in treatment trials between oseltamivir and on-treatment psychiatric adverse events overall, although the $95 \%$ confidence interval is wide ( 0.43 to 2.03 , see web extra fig 25). The two "pivotal" treatment trials WV15670 and WV15671 showed a dose-response effect at the $75 \mathrm{mg}$ (standard dose) and $150 \mathrm{mg}$ (high dose) oseltamivir twice daily dose $(\mathrm{P}=0.038)$. There was no indication of a dose-response effect of treatment on psychiatric adverse events in the only prophylaxis study with multiple dose treatment groups (WV15673/WV15697).

Oseltamivir in the treatment of children induced vomiting compared with placebo $\left(1.70,1.23\right.$ to $2.35, \mathrm{I}^{2}=0 \% ; 5.34 \%, 1.75 \%$ to $10.29 \%$; NNTH 19,10 to 57 , see web extra fig 26).

In prophylaxis trials there was an increased risk of headaches on-treatment $\left(1.18,1.05\right.$ to $1.33, \mathrm{I}^{2}=0 \% ; 3.15 \%, 0.88 \%$ to $5.78 \%$; NNTH 32, 18 to 1150 , see web extra fig 27), nausea on-treatment $\left(1.96,1.20\right.$ to $3.20, \mathrm{I}^{2}=49 \% ; 4.15 \%, 0.86 \%$ to $9.51 \%$; NNTH 25, 11 to 116 , see web extra fig 28), and patients with psychiatric adverse events during the combined on-treatment and off-treatment periods $(1.80,1.05$ to 3.08 , $\mathrm{I}^{2}=0 \% ; 1.06 \%, 0.07 \%$ to $2.76 \%$; NNTH 94,36 to 1538 ) associated with oseltamivir (table $3 \Downarrow$; see web extra fig 29). There was also a dose-response effect for headaches in study WV15673/WV15697 ( $\mathrm{P}=0.013)$ and an increased risk of renal events on-treatment $\left(3.17,0.96\right.$ to $10.49, \mathrm{I}^{2}=0 \% ; 0.67 \%,-0.01 \%$ to $2.93 \%$; NNTH 150 , NNTH 35 to $\infty$ to NNTB $>1000$, see web extra fig 30). In a sensitivity analysis using Peto's method, the result for renal events was statistically significant $(\mathrm{P}=0.02)$.

Tables $4 \Downarrow$ and $5 \Downarrow$ summarise the results for the treatment and prophylaxis indications, respectively. 


\section{Deaths}

Five deaths were reported, only one of these was for a respiratory cause in a chronically ill patient without influenza who was treated with placebo. The four other deaths occurred in prophylaxis trials in elderly patients; two in the placebo arm and two in the oseltamivir arm. In all cases the cause was unrelated to influenza; however, the two patients who died in the oseltamivir arm both had acute renal failure on-treatment before death.

We could not report on viral nasal voidance and viral resistance. Viral resistance was not consistently reported in the clinical study reports and viral nasal voidance was only reported for a subset of the unbalanced subpopulation of participants deemed to be influenza infected.

All clinical study reports will short be available through the Dryad repository at www.datadryad.org.

\section{Discussion}

The evidence we have presented shows that oseltamivir has symptom relieving effects. This may also explain the observed effect on investigator mediated unverified pneumonia (the problem that triggered our change of evidence seeking methods $\left.{ }^{715}\right)$. For most trials $(14 / 20)$, participants were asked to report whether or not they experienced any secondary illnesses such as "pneumonia." This self reporting often led to data collection on non-specific forms that did not include a question prompting the investigator to record verification of diagnosis details. In some trials, however, blank case report forms contained a specific form for diagnosis of "pneumonia"; in these trials, the effect on "pneumonia" was no longer statistically significant. Treatment with oseltamivir did not reduce the risk of any complication classified as serious or that led to study withdrawal. Metaregression of the 32 included studies of neuraminidase inhibitors showed that treatment effects for "pneumonia" differed by method of diagnostic confirmation data capture, with no difference in risk for the subgroup of studies that included radiography confirmation in the data collection. Of course blank forms do not show what was in the filled out forms, but the evidence indicates no effect whenever based on "harder" data capture pathway and no evidence of an effect on serious complications, admissions to hospital, or withdrawals from the trials.

Oseltamivir may have anti-inflammatory properties that make people with influenza-like illness feel better by shortening the duration of symptoms and reducing the occurrence of symptoms. Another explanation for this finding may be that symptom relief results from bias introduced by unblinding due to toxicity of the active principle. Unblinding is closely linked to the exaggeration of symptoms. ${ }^{16}$

This effect perhaps extends to cardiac rhythm (electrocardiographic anomalies), despite the short duration of treatment (five days). However, in trial WV16277 that collected electrocardiographic outcomes in a large subset of patients, oseltamivir increased QTc prolongation, including borderline (risk difference $4.0 \%, 95 \%$ confidence interval $0.71 \%$ to $7.30 \%$; NNTH 25, 95\% confidence interval 14 to 140) compared with placebo during on-treatment periods.

Oseltamivir's effect on complications such as bronchitis and "pneumonia," which were originally considered in trial protocols to be secondary or tertiary endpoints (if they were prespecified at all), would have been clarified with better clinical definitions and investigations, as was done for serious adverse events. These benefited from a paragraph length narrative, which reported most of the salient features of the event.

In prophylactic trials, oseltamivir reduced the risk of symptomatic influenza but there is no evidence that it reduces symptomatic influenza-like illness. Oseltamivir reduces the number of participants receiving prophylaxis who tested positive (based on increases in antibody titre or culture test results, or both). However this finding is weakened by oseltamivir's interference with the viral replication on the swab and effect on antibody production. In addition, oseltamivir does not affect asymptomatic influenza and there is no evidence that it interferes with person to person spread.

Similar to the FDA, ${ }^{17}{ }^{18}$ because of the problems with the design of study WV15799 we could not draw any conclusions on the ability of oseltamivir to interrupt viral transmission.

This is important, as the results of trial WV15799 formed part of the $\mathrm{WHO}^{3}$ rationale for use of the drug to interrupt transmission from person to person and to allow time before the arrival of vaccines in the event of a pandemic, furnishing a seemingly powerful rationale for stockpiling oseltamivir. This shows the importance of availability of full clinical study reports, something WHO did not have.

\section{Strengths and weaknesses of this review}

For the first time a Cochrane review (on neuraminidase inhibitors, of which this review is part) is based on all relevant full clinical study reports of a family of drugs, integrated by regulatory comments. Also for the first time, all clinical study reports of trials in a manufacturer's programme (regardless of their relevance to the review) are available to readers without any restriction (apart from minimal redactions to further protect against the risk of re-identification of participants). The role of the $B M J$ in keeping the issue in the public eye for four years until it was resolved should be recognised. Examples of benefits in accessing full clinical study reports include assessment of reliability of some outcome definitions (for example,

"pneumonia"), a considerable amount of data on potential harms, and avoided reliance of conclusions on published papers, which themselves may have hitherto unseen unpublished material included.

Despite the enormous amount of information at our disposal we noted items that were not included in all full clinical study reports (see risk of bias). These may have introduced bias in the dataset and hence in our review. Other important missing documents included a study manual of procedures and minutes of safety data monitoring committee meetings. The placebo capsules contained dehydrocholic acid and dibasic calcium phosphate dehydrate, which can cause gastrointestinal symptoms, and some appeared to have different coloured caps from their active comparators.

The main limitation of our study is our relative inexperience in dealing with large quantities of information and our lack of familiarity with certain trial documents such as blank case report forms. A further limitation of our review is that the methods we have developed to assess and summarise information from clinical study reports may not apply to non-industry trials (which may not be reported in clinical study reports). In addition, incomplete reporting of viral resistance and viral nasal voidance meant that we could not analyse these outcomes.

We used means and standard deviations to summarise time to first alleviation of symptoms by treatment group. A limitation of this is that participants who do not reach the endpoint cause under-estimation of means. However the proportion of censored patients was low in all trials and similar in both treatment 
groups, hence we do not believe this has led to bias. Alternatively we could have used hazard ratios, but the proportional hazards assumption is unlikely to have been met and reporting treatment effects as hazard ratios is not clinically useful. Another alternative is to use medians, but these too have limitations as they only represent the middle of the distribution.

Our previous decision to analyse the effects of oseltamivir on the intention to treat population ${ }^{6}$ has been justified by our observations of the effect on antibody responses in participants in treatment trials. This effect makes the oseltamivir and placebo arms of the trial unbalanced for analyses on the subpopulation of participants deemed to be influenza infected, because diagnosis was in part based on an increase in antibody titres over time. The effect on antibodies seems to be carried over to children with influenza-like illness. Our finding on antibody response conflicts with some of the comments in a Roche formerly confidential investigators' brochure: "The distribution of antibody titers at baseline and the end of the study were similar for both treatment groups. Geometric mean rises in antibody titer were also similar in the 2 treatment arms. There is therefore no evidence to suggest that oseltamivir prevents the formation of an antibody response." ${ }^{19}$ However the same brochure reports: "The geometric mean-fold increase from baseline levels in type-specific influenza virus antibody titers is reduced in the $75 \mathrm{mg}$ oseltamivir group relative to the placebo group in this pool of studies, this difference being statistically significant at the $5 \%$ level" $^{\prime 19}$ (see also web extra). The reason for such contradictions is unclear, but we have shown a clear effect that could mean oseltamivir affects the antibody response to influenza virus.

Sufficient plasma concentrations of oseltamivir carboxylate from orally administered oseltamivir phosphate may act directly on the host's endogenous neuraminidase to reduce (or suppress) the immune response. The potential hypothermic or antipyretic effect of free oseltamivir as a central nervous system depressant may also contribute to the apparent reduction of symptoms.

The apparent duration of effect on symptom relief afforded by oseltamivir is open to question because data on relapse after the five day treatment period were not reported in the clinical study reports. There was a mix-up with follow-up cards in the "pivotal" trials WV15670, WV15671, and WV15730, which does not allow for drawing any conclusions on the durability of symptom relief. ${ }^{18}$ This important information came to light from the FDA Summary Basis of Approval papers and not from the clinical study reports of the relevant trials. This points to the incomplete nature of reporting in the clinical study reports and the important role of Summary Basis of Approval information.

Oseltamivir relieves symptoms in otherwise healthy children but has no effect on children with asthma who have influenza-like illness, a population that should most benefit from its intake. An explanation for this finding is in the nature of the young asthmatic population, which is well cared for and used to a regular intake of powerful drugs and close follow-up. The incremental benefit of oseltamivir assumption is thus likely to be undetectable in such a population. Oseltamivir had no significant effect on admissions to hospital, an outcome that is important but poorly defined in the oseltamivir protocols and inconsistently reported in the clinical study reports.

The oseltamivir trials did not detect any influenza related mortality events, a reflection of the benign nature of influenza and influenza-like illness and perhaps trial design. In prophylaxis, oseltamivir prevented influenza symptoms in adults and households. However incomplete reporting of influenza-like illness did not allow us to properly determine the effect of oseltamivir. Its capacity to prevent the laboratory confirmation of symptomatic influenza-like illness may be due to a direct effect on antibodies, symptoms, and infection status of people exposed to the wild agents, but there was no visible effect of oseltamivir on complications or admissions to hospital.

Oseltamivir has a distinct toxicity profile. It causes gastrointestinal disturbances in both prophylaxis and treatment roles. In prophylaxis, it caused headaches, renal events (especially decreased creatinine clearance), and psychiatric harms in adults. In the psychiatric events MedDRA System Organ Class (www.meddra.org/how-to-use/basics/hierarchy) several rare Preferred or Lowest Level Terms representing single events (nervousness, aggression, suicide ideation, paranoia) reported in the intervention arm, added to other more frequently reported but not significantly different events (such as depression) gave a large effect and relatively small number needed to harm of 94 (95\% confidence interval 36 to 1538). The importance of such a finding lies in the distribution of oseltamivir to large numbers of asymptomatic individuals following implementation of pandemic plans. The effects on neuropsychiatric harms seems to be real because there is a dose-response effect on headaches in trials WV15673/WV15697 $(\mathrm{P}=0.013)$, in which placebo, $75 \mathrm{mg}$ twice daily and $150 \mathrm{mg}$ twice daily, was administered, and in the brief narratives provided with serious adverse events. The apparent antidiarrhoea effect could potentially be due to a placebo that contained dehydrocholic acid, a gastrointestinal agent that may have increased incidence of diarrhoea in the placebo group, or it could be due to depression of intestinal peristalsis. We also identified eight cases of metabolic disturbance (hyperglycaemia) out of 2000 recipients of oseltamivir in five prophylaxis trials compared with no cases in 1434 recipients of placebo. Given the low numbers, we did not meta-analyse the data, but a rate of 4 per 1000 is high enough to be worrying.

The question of why oseltamivir treatment trials did not show a statistically significant association between treatment and psychiatric harms is not answerable. It is possible that influenza-like illness and influenza symptoms masked the harms in those who were already symptomatic and therefore recruited in the treatment trials. Reporting rules (such as "compliharms") may have played a role (for a full discussion see our Cochrane review) ${ }^{14}$ Or it could be that these events are rare in the populations studied and power was insufficient to detect an association. The confidence interval was wide ( 0.43 to 2.03 ) and does not rule out a doubling in risk as a result of treatment—as was found in the prophylaxis trials. A further explanation is that the standard dose of treatment taken for five days is largely tolerable and that risk of psychiatric harm increases with increasing dose (as the data from trials WV15670 and WV15671 suggest) and increasing duration of treatment (as the prophylaxis trials suggest).

Toovey and colleagues assessed the issue and failed to find an association between neuropsychiatric adverse events and exposure to oseltamivir in the clinical trial data. ${ }^{20}$ The outcomes studied were not based on the a priori definition of psychiatric adverse events, as defined in the clinical study reports that we used. Toovey and colleagues' definition was constructed post hoc based on a selected group of adverse events taken from the psychiatric, neurological, and injury body systems in the reports. They report, however, that their post hoc definition of neuropsychiatric adverse events was approved by the FDA. The issues are described and debated elsewhere. ${ }^{21} 22$ Toovey and colleagues were at the time employees of Roche. 
Treatment trials were mostly under-recruited (achieved sample size below planned sample size with the explanation that influenza circulation was considerably below expected levels) and often their results were pooled in two or even three trials, and yet they showed very high rates of influenza positivity (up to $80 \%$ ). One possible explanation for this lies in the intensive surveillance carried out in the predefined trial centre areas and the restricted time span of recruitment during periods of high likelihood of influenza positivity. This may be why many centres with low levels of recruitment (two or three participants each) are listed in the clinical study reports. This is a consequence of poor generalisability of results to everyday life (where influenza positivity is not as high among patients presenting with influenza-like illness).

In a primary or secondary prophylaxis indication the postulated central effect of oseltamivir is confined to suppressing symptoms, because infection, according to Roche, is not prevented (see web extra). However, the central problem remains the mode of action of the drug and incompatibility of the two contrasting claims on its activity against antibody production. If oseltamivir does not interfere with antibody production (see for example web extra on Roche statements and reference $23^{23}$ ), why do recipients of oseltamivir with influenza-like illness receiving treatment have such a consistently reduced odds of being classified as influenza infected? We have presented evidence clearly fitting a mode of action affecting several body systems (central nervous system, gastrointestinal, renal, immune, and metabolic).

\section{Conclusions}

Given that oseltamivir is now recommended as an essential medicine for the treatment of seriously ill patients or those in higher risk groups with pandemic influenza, ${ }^{45}$ the issues of mode of action, lack of sizeable benefits, and toxicity are of concern. This is made worse by the record and stated intentions of governments to distribute oseltamivir to healthy people to prevent complications and interrupt transmission on the basis of a published evidence base that has been affected by reporting bias, ghost authorship, and poor methods.

We believe these findings provide reason to question the stockpiling of oseltamivir, its inclusion on the WHO list of essential drugs, and its use in clinical practice as an anti-influenza drug.

We thank Matthew Thompson, Rokuro Hama, Chris Del Mar, Liz Dooley, Ruth Davis, Peter Collignon and Toby Lasserson. The National Institute for Health Research (NIHR) for Primary Care Research provides financial support for Carl Heneghan and funding for an investigators' meeting in Oxford, UK.

This paper is based on Cochrane Review A159 which should be published simultaneously in the Cochrane Database of Systematic Reviews (see web extra for peer review history of reviews on neuraminidase inhibitors relevant to this review).

Contributors: TJ, PD, and MJ were authors of the separate relevant Cochrane review in healthy adults. TJ, PD, MJ, and CJH contributed to the writing of the protocol for this review and devised the approach strategies to the data sources. TJ reviewed regulatory material. TJ, PD, and MJ applied inclusion criteria. All authors extracted data and appraised bias. CJH, IO, and EAS checked the data. MJ carried out the statistical analyses. $\mathrm{IO}$ and TJ prepared the final text and all authors contributed to the final draft. $\mathrm{CJH}$ is guarantor.

Funding: This project was funded by the NIHR Health Technology Assessment programme and will be published in full in the Health Technology Assessment journal series (more details are available at www.nets.nihr.ac.uk/projects/hta/108001). The views and opinions expressed therein are those of the authors and do not necessarily reflect those of the Department of Health. The study sponsor had no role in study design; the collection, analysis, and interpretation of data; the writing of the article; and the decision to submit the article for publication. All the authors have no ties to the manufacturer or the sponsor (apart from those disclosed) and had access to all parts of the deidentified clinical study reports from the oseltamivir trial programme.

Competing interests: All authors have completed the ICMJE uniform disclosure form at www.icmje.org/coi_disclosure.pdf and declare that all review authors have applied for and received competitive research grants. TJ, PD, MJ, and CJH are co-recipients of the NIHR grant to carry out this review. TJ receives royalties from his books published by Blackwells and II Pensiero Scientifico Editore, Rome and is occasionally interviewed by market research companies for anonymous interviews about phase 1 or 2 pharmaceutical products. In 2011-13 TJ acted as an expert witness in a litigation case related to oseltamivir phosphate; Tamiflu [Roche] and in a labour case on influenza vaccines in healthcare workers in Canada. In 1997-99 TJ acted as consultant for Roche, in 2001-02 for GSK, and in 2003 for Sanofi-Synthelabo for pleconaril (an antirhinoviral that did not get approval from FDA). $\mathrm{TJ}$ is a consultant for IMS Health. PD received $€ 1500$ ( $£ 1241 ; \$ 2052)$ from the European Respiratory Society in support of his travel to the society's September 2012 annual congress in Vienna, where he gave an invited talk on oseltamivir. PD is an associate editor of the BMJ. TJ, MJ, CJH, and PD are co-recipients of a UK National Institute for Health Research grant (HTA-10/80/01 Update and amalgamation of two Cochrane reviews: neuraminidase inhibitors for preventing and treating influenza in healthy adults and children www.nets.nihr.ac.uk/projects/hta/108001). CJH receives payment for running educational courses at the University of Oxford and University of Oxford ISIS consulting services for external teaching and training. He also receives royalties for books (Evidence Based Toolkit series by Blackwell BMJ Books). MJ, IO, and EAS have no additional interests to disclose.

Ethical approval: Ethical approval and patient consent forms are not provided as they are not necessary for a Cochrane review.

Data sharing: All clinical study reports will shortly be available through the Dryad repository (www.datadryad.org).

Transparency: The lead author (the manuscript's guarantor) affirms that the manuscript is an honest, accurate, and transparent account of the synthesis of the clinical study reports in the review; that no important aspects of the included clinical study reports have been omitted; and that any discrepancies from the study as planned (and, if relevant, registered) have been explained.

1 US Department of Health and Human Services. HHS pandemic influenza plan. 2005. www.hhs.gov/pandemicflu/plan/pdf/HHSPandemiclnfluenzaPlan.pdf.

Donaldson L. A pandemic on the horizon. J R Soc Med 2006;99:222-5.

3 World Health Organization. WHO interim protocol: rapid operations to contain the initial emergence of pandemic influenza. 2007. www.who.int/entity/csr/disease/avian_influenza/ guidelines/RapidContProtOct15.pdf.

4 World Health Organization. WHO model list of essential medicines. Adults, 18th edn (April 2013). Revised Oct 2013. http://apps.who.int//iris/bitstream/10665/93142/1/EML_18_eng. pdf].

5 World Health Organization. WHO model list of essential medicines for children. 4th list (April 2013). Revised Oct 2013. http://apps.who.int/iris/bitstream/10665/93143/1/EMLc_ 4 eng.pdf.

6 Jefferson T, Jones MA, Doshi P, Del Mar CB, Heneghan CJ, Hama R, Thompson MJ. Neuraminidase inhibitors for preventing and treating influenza in healthy adults and children. Cochrane Database Syst Rev 2014;4:CD008965.

7 Doshi P, Jones MA, Jefferson T. Rethinking credible evidence synthesis. $B M\lrcorner$ 2012;344:d7898.

8 Doshi $P$, Jefferson T. Clinical study reports of randomised controlled trials: an exploratory review of previously confidential industry reports. BMJ Open 2013;3:e002496.

9 European Medicines Agency. European Medicines Agency policy on access to documents (related to medicinal products for human and veterinary use) POLICY/0043. 2010 www. ema.europa.eu/docs/en GB/document library/Other/2010/11/WC500099473.pdf.

$10 \mathrm{~F}$ Hoffmann-La Roche. Roche global policy on sharing of clinical trials data. $2013 \mathrm{http}: /$ roche-trials.com/dataSharingPolicy.action.

11 Godlee F. Clinical trial data for all drugs in current use. [Editorial.] BMJ 2012;345:e7304 (29 October).

12 Shun-Shin M, Thompson M, Heneghan C, Perera R, Harnden A, Mant D. Neuraminidase inhibitors for treatment and prophylaxis of influenza in children: systematic review and meta-analysis of randomised controlled trials. BMJ 2009;339:b3172. 


\section{What is already known on this topic}

Neuraminidase inhibitors are used globally for the treatment and prophylaxis of influenza

The evidence for their effectiveness in preventing complications of influenza is sparse, and information on their adverse events are

lacking

\section{What this study adds}

To address reporting bias in trials of oseltamivir we included only complete clinical study reports of randomised controlled trials and relevant regulatory comments (approximately 150000 pages)

To our knowledge this is the first time that such methods have been used in a Cochrane review

Our results show that oseltamivir reduces the proportion of participants with symptomatic influenza when used for prophylaxis and has modest symptomatic effects when used for treatment, but it causes nausea and vomiting and increases the risk of headaches and renal and psychiatric syndromes

13 Jefferson T, Jones M, Doshi P, Del Mar C. Neuraminidase inhibitors for preventing and treating influenza in healthy adults: systematic review and meta-analysis. $B M J$ 2009;339:b5106

14 Jefferson T, Jones MA, Doshi P, Del Mar CB, Hama R, Thompson MJ, et al. Neuraminidase inhibitors for preventing and treating influenza in healthy adults and children. Cochrane Database Syst Rev 2014;4:CD008965.

15 Jefferson T, Doshi P, Thompson M, Heneghan C. Ensuring safe and effective drugs: who can do what it takes? BMJ 2011;342:c7258.

16 Hróbjartsson A, Thomsen ASS, Emanuelsson F, Tendal B, Hilden J, Boutron I, et al. Observer bias in randomised clinical trials with binary outcomes: systematic review of trials with both blinded and non-blinded outcome assessors. BMJ 2012;344:e1119.

17 Food and Drug Administration. Drug approval package. Tamiflu (oseltamivir). Application No. 021087-SE1-002. 2000. www.accessdata.fda.gov/drugsatfda_docs/nda/2000/21087SE1-002_review.pdf.

18 Food and Drug Administration. Tamiflu (oseltamivir phosphate) capsule. Medical Review Part 2 (Application No. 021087). 2000. www.accessdata.fda.gov/drugsatfda_docs/nda/ 99/21087_Tamiflu_medr_P1.pdf.

19 Investigators guide. 2009. www.roche.be/fmfiles/re7189007/CU056/10_Investigators_ brochure.pdf.
20 Toovey S, Rayner C, Prinssen E. Assessment of neuropsychiatricadverse events in influenza patients treated with oseltamivir. A comprehensive review. Drug Saf 2008;31:1097-114

21 Toovey S. The author's reply. Drug Saf 2012;35:1188-90.

22 Jones M, Hama R, Jefferson T, Doshi P. Neuropsychiatric adverse events and oseltamivir for prophylaxis. Drug Saf 2012;35:1187-8.

23 F Hoffman-La Roche. Tamiflu label (for FDA NDA No 021087). 2011. www.accessdata. fda.gov/drugsatfda_docs/label/2011/021087s057lbl.pdf.

\section{Accepted: 3 April 2014}

\section{Cite this as: BMJ 2014;348:g2545}

This is an Open Access article distributed in accordance with the Creative Commons Attribution Non Commercial (CC BY-NC 3.0) license, which permits others to distribute, remix, adapt, build upon this work non-commercially, and license their derivative works on different terms, provided the original work is properly cited and the use is non-commercial. See: http://creativecommons.org/licenses/by-nc/3.0/. 


\section{Tables}

\begin{tabular}{|c|c|c|c|c|c|c|c|c|c|}
\hline \multirow[t]{2}{*}{ Trial (drug) } & \multirow[t]{2}{*}{ Inclusion criteria } & \multirow[t]{2}{*}{ Exclusion criteria } & \multirow{2}{*}{$\begin{array}{c}\text { Age } \\
\text { range } \\
\text { (years) }\end{array}$} & \multicolumn{2}{|c|}{ Intervention } & \multicolumn{2}{|c|}{ Control } & \multirow{2}{*}{$\begin{array}{l}\text { Outcomes } \\
\text { reported }\end{array}$} & \multirow{2}{*}{$\begin{array}{l}\text { Duration } \\
\text { of } \\
\text { follow-up } \\
\text { (days) }\end{array}$} \\
\hline & & & & $\begin{array}{l}\text { No } \\
\text { recruited }\end{array}$ & $\begin{array}{c}\text { No } \\
\text { confirmed }^{\star}\end{array}$ & $\begin{array}{l}\text { No } \\
\text { recruited }\end{array}$ & $\begin{array}{c}\text { No } \\
\text { confirmed }^{*}\end{array}$ & & \\
\hline JV15823, 2000, Japan & $\begin{array}{l}\text { Influenza-like } \\
\text { illness of } \leq 36 \\
\text { hours+temperature } \\
\geq 38.0^{\circ} \mathrm{C}\end{array}$ & $\begin{array}{l}\text { Pregnancy, } \\
\text { suspected bacterial } \\
\text { infection, use of } \\
\text { antivirals, influenza } \\
\text { immunisation, drug } \\
\text { misuse }\end{array}$ & $\geq 16$ & 154 & 122 & 159 & 130 & $\begin{array}{l}\text { Time to } \\
\text { alleviation of } \\
\text { symptoms }\end{array}$ & 6 \\
\hline M76001, 1998/9, USA & $\begin{array}{l}\text { Influenza-like } \\
\text { illness of } \leq 36 \\
\text { hours+temperature } \\
\geq 38.0^{\circ} \mathrm{C}\end{array}$ & $\begin{array}{l}\text { Unstable chronic } \\
\text { illness, transplant } \\
\text { recipients, } \\
\text { immunosuppression, } \\
\text { pregnancy, allergy, } \\
\text { drug misuse }\end{array}$ & $\geq 13-80$ & 965 & 702 & 482 & 361 & $\begin{array}{l}\text { Time to } \\
\text { alleviation of } \\
\text { symptoms }\end{array}$ & 21 \\
\hline ML16369, 2001, China & $\begin{array}{l}\text { Influenza-like } \\
\text { illness of } \leq 36 \\
\text { hours+temperature } \\
\geq 37.8^{\circ} \mathrm{C}\end{array}$ & $\begin{array}{l}\text { Asthma, chronic } \\
\text { obstructive } \\
\text { pulmonary disease, } \\
\text { pregnancy, } \\
\text { immunosuppression, } \\
\text { suspected bacterial } \\
\text { infection }\end{array}$ & $\geq 18-\geq 65$ & 216 & 134 & 235 & 139 & $\begin{array}{l}\text { Median } \\
\text { duration of } \\
\text { symptoms }\end{array}$ & 21 \\
\hline $\begin{array}{l}\text { NV16871, 2004, } 10 \text { European } \\
\text { countries }\end{array}$ & $\begin{array}{l}\text { Asthmatic children, } \\
\text { influenza-like illness } \\
\text { of } \leq 36 \\
\text { hours+temperature } \\
\geq 37.8^{\circ} \mathrm{C}\end{array}$ & $\begin{array}{l}\text { Immunosuppression, } \\
\text { use of antibiotics, } \\
\text { transplant recipients, } \\
\text { allergy, use of } \\
\text { antivirals }\end{array}$ & $6-17$ & 165 & 43 & 164 & 51 & $\begin{array}{l}\text { Time to } \\
\text { alleviation of } \\
\text { symptoms }\end{array}$ & 23 \\
\hline WV15670, 1997/8, USA & $\begin{array}{l}\text { Influenza-like } \\
\text { illness of } \leq 36 \\
\text { hours+temperature } \\
\geq 38.0^{\circ} \mathrm{C}\end{array}$ & $\begin{array}{l}\text { Pregnancy, } \\
\text { suspected bacterial } \\
\text { infection, use of } \\
\text { antivirals, influenza } \\
\text { immunization, drug } \\
\text { abuse }\end{array}$ & $\geq 18-\geq 65$ & 484 & 314 & 235 & 161 & $\begin{array}{l}\text { Time to } \\
\text { alleviation of } \\
\text { symptoms }\end{array}$ & 25 \\
\hline WV15671, 1997/8, USA & $\begin{array}{l}\text { Influenza-like } \\
\text { illness of } \leq 36 \\
\text { hours+temperature } \\
\geq 38.0^{\circ} \mathrm{C}\end{array}$ & $\begin{array}{l}\text { Pregnancy, } \\
\text { suspected bacterial } \\
\text { infection, use of } \\
\text { antivirals, influenza } \\
\text { immunisation, drug } \\
\text { misuse }\end{array}$ & $\geq 18-\geq 65$ & 411 & 245 & 204 & 129 & $\begin{array}{l}\text { Time to } \\
\text { alleviation of } \\
\text { symptoms }\end{array}$ & 21 \\
\hline $\begin{array}{l}\text { WV15707, 1998/9, Australia, } \\
\text { South Africa, South America }\end{array}$ & $\begin{array}{l}\text { Influenza-like } \\
\text { illness of } \leq 36 \\
\text { hours+temperature } \\
\geq 37.5^{\circ} \mathrm{C}\end{array}$ & $\begin{array}{l}\text { Unstable chronic } \\
\text { illness, transplant } \\
\text { recipients, } \\
\text { immunosuppression }\end{array}$ & $\geq 65$ & 17 & 6 & 9 & 6 & $\begin{array}{l}\text { Time to } \\
\text { alleviation of } \\
\text { symptoms }\end{array}$ & 25 \\
\hline $\begin{array}{l}\text { WV15730, 1998, Australia, } \\
\text { South Africa }\end{array}$ & $\begin{array}{l}\text { Influenza-like } \\
\text { illness of } \leq 36 \\
\text { hours+temperature } \\
\geq 38.0^{\circ} \mathrm{C}\end{array}$ & $\begin{array}{l}\text { Pregnancy, transplant } \\
\text { recipients, } \\
\text { immunosuppression, } \\
\text { drug misuse, use of } \\
\text { antivirals }\end{array}$ & $\geq 18-\geq 65$ & 31 & 19 & 27 & 19 & $\begin{array}{l}\text { Time to } \\
\text { alleviation of } \\
\text { symptoms }\end{array}$ & 21 \\
\hline WV15758, 1998, USA, Canada & $\begin{array}{l}\text { Influenza-like } \\
\text { illness of }<48 \\
\text { hours+temperature } \\
\geq 37.8^{\circ} \mathrm{C}\end{array}$ & $\begin{array}{l}\text { Immunosuppression, } \\
\text { allergy, use of } \\
\text { antivirals, transplant } \\
\text { recipients }\end{array}$ & $1-12$ & 344 & 217 & 351 & 235 & $\begin{array}{l}\text { Time to } \\
\text { alleviation of } \\
\text { symptoms }\end{array}$ & 28 \\
\hline $\begin{array}{l}\text { WV15759/WV15871, 1999, } 7 \\
\text { European countries, USA, } \\
\text { Argentina, Chile, Australia, New } \\
\text { Zealand, South Africa, Hong } \\
\text { Kong }\end{array}$ & $\begin{array}{l}\text { Patients with } \\
\text { asthma, } \\
\text { influenza-like illness } \\
\text { of }<48 \\
\text { hours+temperature } \\
\geq 37.8^{\circ} \mathrm{C}\end{array}$ & $\begin{array}{l}\text { Immunosuppression, } \\
\text { allergy, transplant } \\
\text { recipients, use of } \\
\text { antivirals }\end{array}$ & $6-12$ & 170 & 84 & 164 & 95 & $\begin{array}{l}\text { Time to } \\
\text { alleviation of } \\
\text { symptoms, } \\
\text { time to } \\
\text { return to } \\
\text { normal } \\
\text { activity }\end{array}$ & 28 \\
\hline
\end{tabular}


Table 1 (continued)

\begin{tabular}{|c|c|c|c|c|c|c|c|c|c|}
\hline \multirow[t]{2}{*}{ Trial (drug) } & \multirow[t]{2}{*}{ Inclusion criteria } & \multirow[t]{2}{*}{ Exclusion criteria } & \multirow{2}{*}{$\begin{array}{l}\text { Age } \\
\text { range } \\
\text { (years) }\end{array}$} & \multicolumn{2}{|c|}{ Intervention } & \multicolumn{2}{|c|}{ Control } & \multirow{2}{*}{$\begin{array}{l}\text { Outcomes } \\
\text { reported }\end{array}$} & \multirow{2}{*}{$\begin{array}{l}\text { Duration } \\
\text { of } \\
\text { follow-up } \\
\text { (days) }\end{array}$} \\
\hline & & & & $\begin{array}{l}\text { No } \\
\text { recruited }\end{array}$ & $\begin{array}{c}\text { No } \\
\text { confirmed }^{\star}\end{array}$ & $\begin{array}{l}\text { No } \\
\text { recruited }\end{array}$ & $\begin{array}{c}\text { No } \\
\text { confirmed* }^{*}\end{array}$ & & \\
\hline $\begin{array}{l}\text { WV15812/WV15872, 1999, } \\
\text { Australia, New Zealand, South } \\
\text { Africa, } 10 \text { European Countries, } \\
\text { USA, Canada }\end{array}$ & $\begin{array}{l}\text { Chronic cardiac } \\
\text { and/or respiratory } \\
\text { disease, fever } \\
\geq 38^{\circ} \mathrm{C}\left(100^{\circ} \mathrm{F}\right) \text { if } \\
<65 \text { years or } \\
\geq 37.5^{\circ} \mathrm{C}\left(99.5^{\circ} \mathrm{F}\right) \\
\text { if } \geq 65 \text { years }\end{array}$ & $\begin{array}{l}\text { COAD stage III, } \\
\text { transplant recipients, } \\
\text { liver/renal } \\
\text { dysfunction, drug } \\
\text { misuse, allergy, } \\
\text { immunosuppression }\end{array}$ & $\geq 13$ & 199 & 118 & 202 & 133 & $\begin{array}{l}\text { Time to } \\
\text { alleviation of } \\
\text { symptoms }\end{array}$ & 21 \\
\hline $\begin{array}{l}\text { WV15819/WV15876/WV15978, } \\
\text { 1999/2000, } 14 \text { European } \\
\text { countries, Canada, USA, } \\
\text { Australia, New Zealand, South } \\
\text { Africa }\end{array}$ & $\begin{array}{l}\text { Influenza-like } \\
\text { illness of }<36 \\
\text { hours, fever } \\
\geq 37.5^{\circ} \mathrm{C}\end{array}$ & $\begin{array}{l}\text { Unstable chronic } \\
\text { illness, transplant } \\
\text { recipients, use of } \\
\text { antivirals, drug } \\
\text { misuse, suspected } \\
\text { bacterial infection }\end{array}$ & $\geq 65$ & 362 & 223 & 373 & 254 & $\begin{array}{l}\text { Duration of } \\
\text { illness }\end{array}$ & 21 \\
\hline $\begin{array}{l}\text { WV16277, 2000, } 10 \text { European } \\
\text { countries }\end{array}$ & $\begin{array}{l}\text { Influenza-like } \\
\text { illness of }<36 \\
\text { hours, fever } \\
\geq 37.5^{\circ} \mathrm{C}\end{array}$ & $\begin{array}{l}\text { Immunosuppression, } \\
\text { allergy, transplant } \\
\text { recipients, use of } \\
\text { antivirals, grade IV } \\
\text { cardiac failure NYHA } \\
\text { scale }\end{array}$ & $\begin{array}{l}\geq 13 \text { or } \\
\geq 18\end{array}$ & 226 & 119 & 225 & 109 & $\begin{array}{l}\text { Time to } \\
\text { alleviation of } \\
\text { symptoms }\end{array}$ & 21 \\
\hline
\end{tabular}

$\mathrm{COAD}=$ chronic obstructive airways disease; NYHA=New York Heart Association.

*Participant recruited with influenza-like illness symptoms/signs who has had a fourfold or greater increase in influenza antibody titre or a positive viral culture result, or both. 


\begin{tabular}{|c|c|c|c|c|c|c|c|}
\hline \multirow[t]{2}{*}{ Trial } & \multirow[t]{2}{*}{ Treatment } & \multicolumn{2}{|c|}{ Intervention } & \multicolumn{2}{|c|}{ Control } & \multirow[t]{2}{*}{ Outcomes } & \multirow{2}{*}{$\begin{array}{c}\text { Duration } \\
\text { of } \\
\text { follow-up } \\
\text { (days) }\end{array}$} \\
\hline & & $\begin{array}{l}\text { Index cases } \\
\left(\text { confirmed }^{*}\right)\end{array}$ & $\begin{array}{l}\text { Paediatric } \\
\text { contacts }\end{array}$ & $\begin{array}{l}\text { Index cases } \\
\left(\text { confirmed }^{\star}\right)\end{array}$ & $\begin{array}{l}\text { Paediatric } \\
\text { contacts }\end{array}$ & & \\
\hline JV15824, 1999/2000, Japan & $\begin{array}{l}\text { Ro64-0796 or placebo once daily } \\
\text { for } 42 \text { days }\end{array}$ & $155(7)$ & - & $153(28)$ & - & $\begin{array}{l}\text { Symptomatic, laboratory } \\
\text { confirmed influenza during } 42 \\
\text { days of prophylaxis }\end{array}$ & 42 \\
\hline $\begin{array}{l}\text { WV15673/WV15697, 1998, } \\
\text { USA }\end{array}$ & $\begin{array}{l}75 \text { mg Ro64-0796 or placebo once } \\
\text { or twice daily for } 42 \text { days. } \\
\text { Exclusion: pregnancy, influenza } \\
\text { vaccination, transplant recipient }\end{array}$ & $1040(7)$ & - & $519(19)$ & - & $\begin{array}{l}\text { Symptomatic, laboratory } \\
\text { confirmed influenza during } 42 \\
\text { days of prophylaxis }\end{array}$ & 42 \\
\hline $\begin{array}{l}\text { WV15708, 1998, Australia, } \\
\text { New Zealand, South } \\
\text { America, Brazil }\end{array}$ & $\begin{array}{l}75 \text { mg Ro64-0796 or placebo once } \\
\text { daily for } 42 \text { days. Exclusion: } \\
\text { pregnancy, influenza vaccination, } \\
\text { transplant recipient }\end{array}$ & $190(1)$ & - & $182(1)$ & - & $\begin{array}{l}\text { Symptomatic, laboratory } \\
\text { confirmed influenza confirmed } \\
\text { by either virus shedding within } \\
\text { two days of symptom onset or } \\
\text { fourfold increase in influenza } \\
\text { antibody titre }\end{array}$ & 42 \\
\hline $\begin{array}{l}\text { WV15799, 1998/9, } 8 \\
\text { European countries, USA, } \\
\text { Canada }\end{array}$ & $\begin{array}{l}\text { Oral dose of } 75 \mathrm{mg} \text { Ro64-0796 or } \\
\text { placebo administered once daily for } \\
\text { seven days. Exclusion: unstable } \\
\text { illness, transplant recipients }\end{array}$ & $209(5)$ & - & $206(7)$ & - & $\begin{array}{l}\text { Incidence of laboratory } \\
\text { confirmed clinical influenza in } \\
\text { contacts of index case }\end{array}$ & 25 \\
\hline $\begin{array}{l}\text { WV15825, 1999, UK, USA, } \\
\text { France, Belgium, Netherlands }\end{array}$ & $\begin{array}{l}75 \text { mg Ro64-0796 or placebo once } \\
\text { daily for } 42 \text { days. Exclusion: } \\
\text { transplant recipients, liver or renal } \\
\text { disease, unstable chronic illness, } \\
\text { immunodeficiency, drug misuse }\end{array}$ & 276 & - & 272 & - & $\begin{array}{l}\text { Incidence of laboratory } \\
\text { confirmed clinical influenza from } \\
\text { fourth day of dosing until } 42 \\
\text { days }\end{array}$ & 42 \\
\hline
\end{tabular}

*Participant recruited with

influenza-like illness

symptoms/signs who has had a fourfold or greater increase in influenza antibody titre or a positive viral culture result, or both. 
Table 3| Psychiatric adverse events in oseltamivir prophylaxis trials

\begin{tabular}{lccc} 
Event type & \multicolumn{3}{c}{ No of events* $(\%)$} \\
\cline { 2 - 4 } Confusion & $5(0.25)$ & $1(0.07)$ & $6(0.17)$ \\
\hline Depression & $14(0.7)$ & $6(0.42)$ & $20(0.58)$ \\
\hline Hallucinations & $2(0.1)$ & $0(0.00)$ & $2(0.06)$ \\
\hline Anxiety & $7(0.35)$ & $8(0.56)$ & $15(0.44)$ \\
\hline Psychosis & $2(0.1)$ & $1(0.07)$ & $3(0.09)$ \\
\hline Schizophrenia & $1(0.05)$ & $0(0.00)$ & $1(0.03)$ \\
\hline Bipolar disorder & $0(0)$ & $1(0.07)$ & $1(0.03)$ \\
\hline Sleeping disorder & $2(0.1)$ & $0(0.00)$ & $2(0.06)$ \\
\hline Aggression & $1(0.05)$ & $0(0.00)$ & $1(0.03)$ \\
\hline Stress symptoms & $3(0.15)$ & $0(0.00)$ & $3(0.09)$ \\
\hline Restlessness & $1(0.05)$ & $0(0.00)$ & $1(0.03)$ \\
\hline Nervousness & $1(0.05)$ & $0(0.00)$ & $1(0.03)$ \\
\hline Suicide ideation & $1(0.05)$ & $0(0.00)$ & $1(0.03)$ \\
\hline Paranoia & $1(0.05)$ & $0(0.00)$ & $1(0.03)$ \\
\hline Alcohol related & $6(0.3)$ & $2(0.14)$ & $8(0.23)$ \\
\hline Total & $47(2.35)$ & $19(1.32)$ & $66(1.92)$ \\
\hline
\end{tabular}

*47 events occurred in 44 patients in the oseltamivir arms. 


\begin{tabular}{|c|c|c|c|c|c|c|}
\hline \multirow[t]{2}{*}{ Outcomes } & \multicolumn{2}{|c|}{ Illustrative comparative risks* $(95 \% \mathrm{Cl})$} & \multirow{2}{*}{$\begin{array}{l}\text { Relative effect: } \\
\text { risk ratio }(95 \% \mathrm{Cl})\end{array}$} & \multirow{2}{*}{$\begin{array}{l}\text { No of } \\
\text { participants } \\
\text { (No of } \\
\text { studies) }\end{array}$} & \multirow{2}{*}{$\begin{array}{l}\text { Risk difference } \\
(\%)(95 \% \mathrm{Cl})\end{array}$} & \multirow{2}{*}{$\begin{array}{l}\text { NNTB or NNTH } \\
(95 \% \mathrm{Cl})\end{array}$} \\
\hline & $\begin{array}{l}\text { Study population } \\
\text { risk }\end{array}$ & $\begin{array}{l}\text { Corresponding } \\
\text { intervention risk }\end{array}$ & & & & \\
\hline \multicolumn{7}{|l|}{ Adults } \\
\hline $\begin{array}{l}\text { Time to first alleviation of } \\
\text { influenza-like illness } \\
\text { symptoms in adults (hours) }\end{array}$ & & $\begin{array}{c}16.76 \text { hours lower (25.1 to } \\
8.42 \text { lower) }\end{array}$ & NA & $3954(8)$ & NA & NA \\
\hline \multicolumn{7}{|l|}{ Complications: } \\
\hline $\begin{array}{l}\text { Investigator mediated } \\
\text { unverified pneumonia on } \\
\text { treatment }\end{array}$ & 22 per 1000 & 12 per 1000 (7 to 20$)$ & 0.55 (0.33 to 0.90$)$ & $4452(8)$ & $1.00(0.22$ to 1.49$)$ & NNTB 100 (67 to 451$)$ \\
\hline \multicolumn{7}{|l|}{ Adverse events: } \\
\hline Nausea (on-treatment) & 64 per 1000 & 101 per 1000 (73 to 138$)$ & $1.57(1.14$ to 2.15$)$ & $4452(8)$ & $-3.66(-7.39$ to -0.9$)$ & NNTH 28 (14 to 112$)$ \\
\hline Vomiting (on-treatment) & 32 per 1000 & 77 per 1000 (56 to 108$)$ & $2.43(1.75$ to 3.38$)$ & $4452(8)$ & $\begin{array}{c}-4.56(-7.58 \text { to } \\
-2.39)\end{array}$ & NNTH 22 (14 to 42) \\
\hline Diarrhoea (on-treatment) & 71 per 1000 & 47 per 1000 (32 to 69$)$ & 0.67 (0.46 to 0.98$)$ & $4452(8)$ & $2.33(0.14$ to 3.81$)$ & NNTB 43 (27 to 709 ) \\
\hline $\begin{array}{l}\text { Cardiac body system } \\
\text { (on-treatment) }\end{array}$ & 13 per 1000 & 7 per 1000 (3 to 13$)$ & $0.49(0.25$ to 0.97$)$ & $3943(6)$ & $0.68(0.04$ to 1.0$)$ & $\begin{array}{c}\text { NNTB } 148 \text { (101 to } \\
2509)\end{array}$ \\
\hline $\begin{array}{l}\text { Psychiatric body system } \\
\text { (on-treatment) }\end{array}$ & 7 per 1000 & 7 per 1000 (3 to 15$)$ & $0.93(0.43$ to 2.03$)$ & $4426(7)$ & 0.05 ( -0.77 to 0.42$)$ & $\begin{array}{c}\text { NNTB } 1922 \text { (NNTB } 236 \\
\text { to } \infty \text { to NNTH 131) }\end{array}$ \\
\hline Headache (off-treatment) & 15 per 1000 & 20 per 1000 (13 to 32$)$ & $1.34(0.83$ to 2.15$)$ & $4368(6)$ & $-0.25(-1.34$ to 0.42$)$ & NNTH 396 ( 75 to 241 ) \\
\hline \multicolumn{7}{|l|}{ Children } \\
\hline $\begin{array}{l}\text { Time to first alleviation of } \\
\text { symptoms in children (hours) }\end{array}$ & & $\begin{array}{l}8.04 \text { hours lower ( } 33.34 \\
\text { lower to } 17.26 \text { higher) }\end{array}$ & NA & $1329(3)$ & NA & NA \\
\hline $\begin{array}{l}\text { Hospital admission in child } \\
\text { treatment (safety population) }\end{array}$ & 9 per 1000 & 17 per 100 (6 to 46$)$ & 1.92 (0.7 to 5.23$)$ & $1359(3)$ & $-0.81(-3.72$ to 0.26$)$ & NNTH 124 (27 to 379) \\
\hline \multicolumn{7}{|l|}{ Complications: } \\
\hline Bronchitis in child treatment & 31 per 1000 & 20 per 1000 ( 8 to 48 ) & 0.65 (0.27 to 1.55$)$ & $1359(3)$ & 1.08 (-1.69 to 2.25$)$ & $\begin{array}{c}\text { NNTB } 93 \text { (NNTB } 45 \text { to } \\
\infty \text { to NNTH 59) }\end{array}$ \\
\hline $\begin{array}{l}\text { Otitis media in child } \\
\text { treatment }\end{array}$ & 163 per 1000 & 130 per 1000 (101 to 166$)$ & 0.8 (0.62 to 1.02$)$ & $1359(3)$ & $3.26(-0.33$ to 6.18$)$ & $\begin{array}{c}\text { NNTB } 31 \text { (NNTB } 17 \text { to } \\
\infty \text { to NNTH 308) }\end{array}$ \\
\hline Pneumonia in child treatment & 37 per 1000 & 39 per 1000 (23 to 68$)$ & $1.06(0.62$ to 1.83$)$ & $1359(3)$ & $-0.22(-3.07$ to 1.41$)$ & $\begin{array}{c}\text { NNTH } 450 \text { (NNTH } 33 \text { to } \\
\infty \text { to NNTB 71) }\end{array}$ \\
\hline \multicolumn{7}{|l|}{ Adverse events: } \\
\hline Diarrhoea in child treatment & 72 per 1000 & 63 per 1000 (42 to 92$)$ & 0.87 (0.58 to 1.28$)$ & $1358(3)$ & 0.93 (-2.01 to 3.02$)$ & $\begin{array}{c}\text { NNTB } 108 \text { (NNTB } 34 \text { to } \\
\infty \text { to NNTH 50) }\end{array}$ \\
\hline Vomiting in child treatment & 76 per 1000 & 130 per 1000 (94 to 179$)$ & 1.7 (1.23 to 2.35$)$ & $1358(3)$ & $\begin{array}{c}-5.34(-10.29 \text { to } \\
-1.75)\end{array}$ & NNTH 19 (10 to 57$)$ \\
\hline
\end{tabular}

NNTB=number needed to treat to benefit; NNTH=number needed to treat to harm; NA=not applicable..

*To estimate treatment effects we first calculated risk ratios and used the average (mean) control event rate and pooled risk ratios reported in figures to calculate risk differences. 


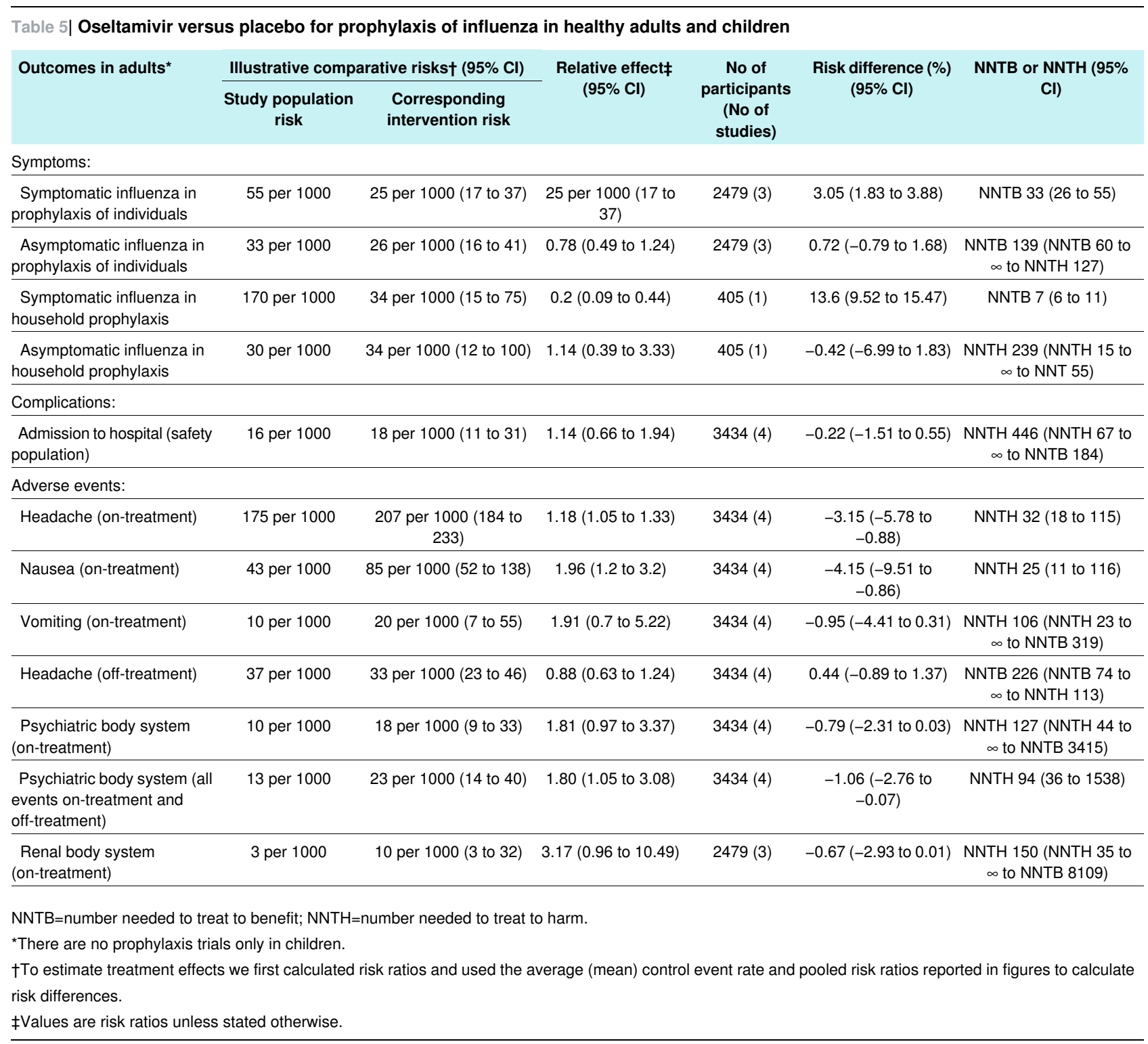




\section{Figures}

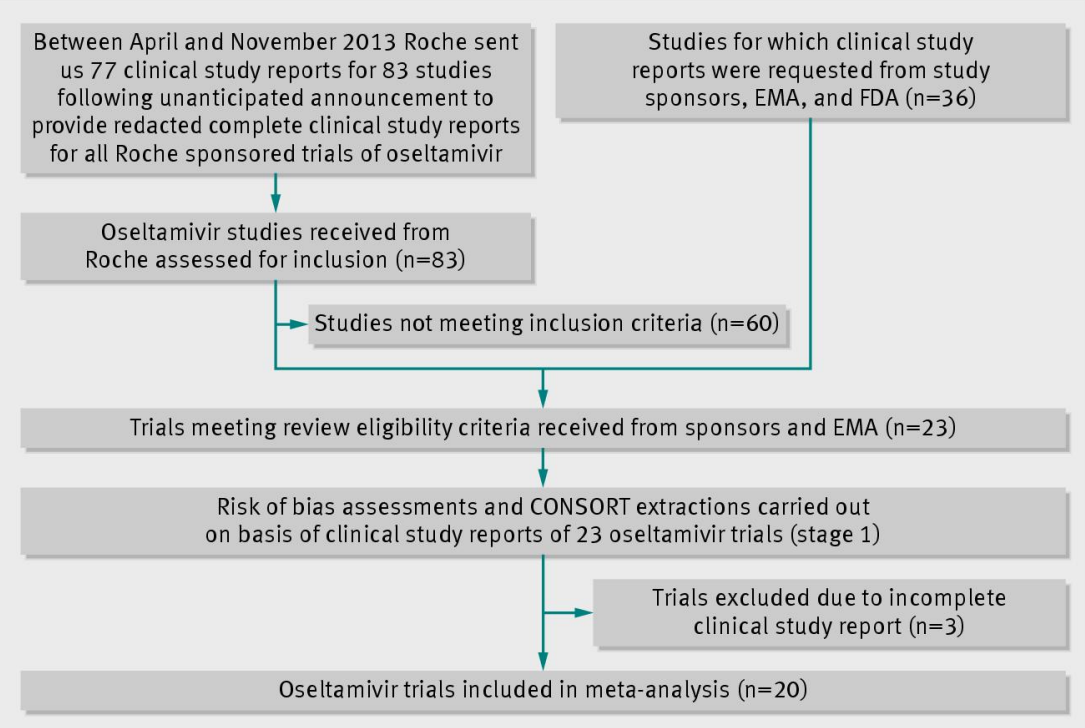

Fig 1 Flowchart for inclusion of oseltamivir clinical study reports 


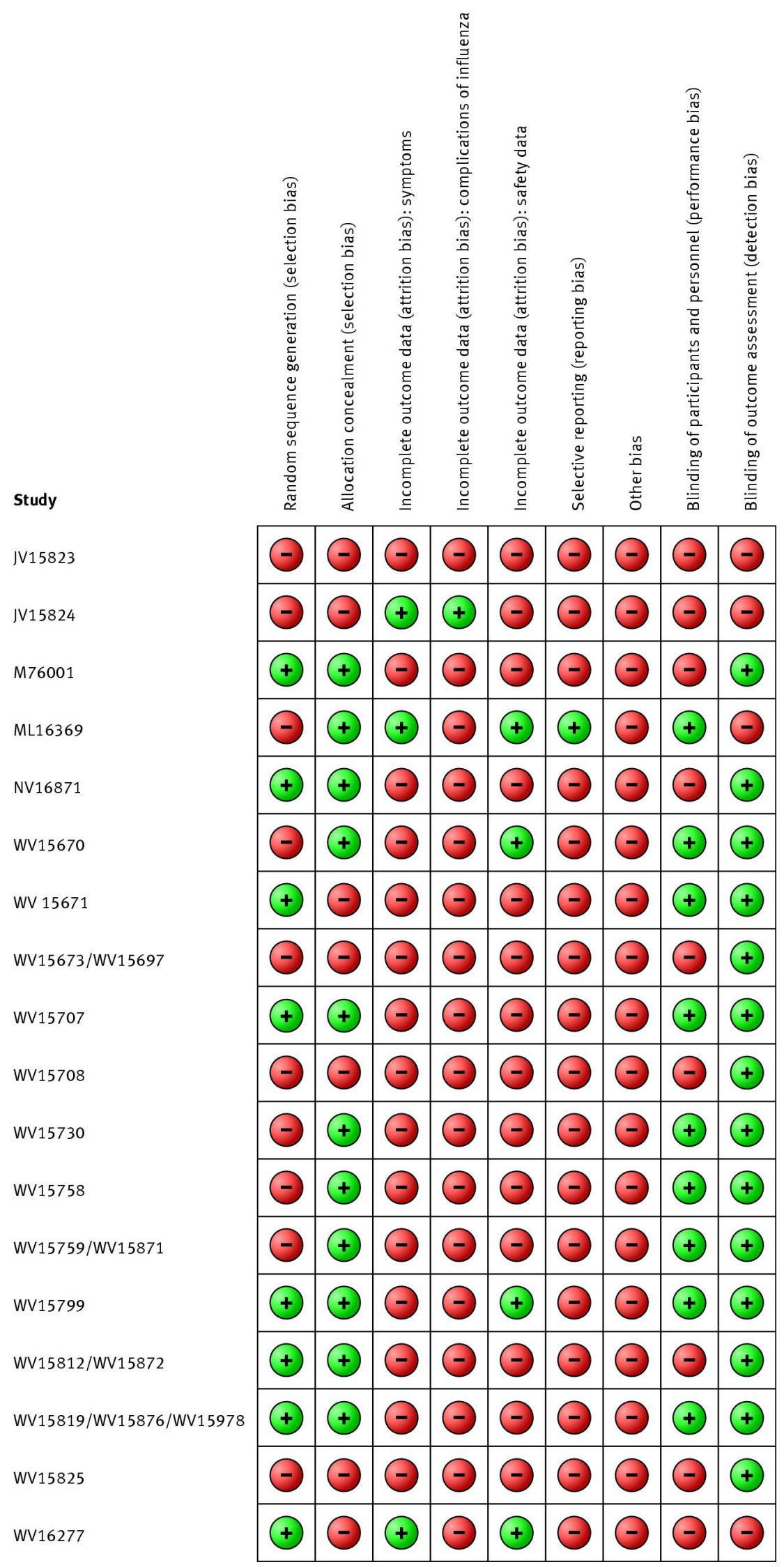

Fig 2 Risk of bias in included studies 